\title{
Does left atrial appendage ligation during coronary bypass surgery decrease the incidence of postoperative stroke?
}

Yen-Yi Juo, MD, MPH, ${ }^{\mathrm{a}, \mathrm{b}}$ Katherine Lee Bailey, BS, ${ }^{\mathrm{c}}$ Young-Ji Seo, BS, ${ }^{\mathrm{c}}$ Esteban Aguayo, BS, ${ }^{\mathrm{c}}$ and Peyman Benharash, MD ${ }^{\mathrm{a}, \mathrm{d}}$

\section{ABSTRACT}

Objective: The study objective was to evaluate the association between surgical left atrial appendage ligation and in-hospital stroke incidence after coronary artery bypass grafting among patients with atrial fibrillation.

Methods: A retrospective cohort study was performed by using the Nationwide Inpatient Sample between 2008 and 2014. All atrial fibrillation patients who underwent coronary artery bypass graft were included and categorized as left atrial appendage ligation or control group. Propensity score-weighted regression analyses were performed to assess the impact of left atrial appendage ligation on stroke incidence.

Results: A total of 234,642 patients were identified, among whom 20,664 $(8.81 \%)$ received concomitant left atrial appendage ligation. The national postoperative stroke incidence was $0.92 \%$. Results of the propensity-weighted regression analysis showed no significant association between LAA ligation and control with regard to postoperative stroke (odds ratio [OR], 0.83; confidence interval $[\mathrm{CI}], 0.57-1.22 ; P=.35$ ), pericardial complications (OR, 1.15; CI, 0.88-1.49; $P=.31$ ), hemorrhage and/or hematoma (OR, 1.08; CI, 0.99-1.17; $P=.07)$, mortality (OR, 1.29; CI, 0.99-1.68; $P=.06$ ), and length of stay (coefficient $-0.21 ; \mathrm{CI},-0.44-0.02 ; P=.08$ ). There was no specific CHA2DS2VASC score cutoff above which left atrial appendage ligation was demonstrated to have lower postoperative stroke incidence.

Conclusions: The postoperative stroke risk after coronary artery bypass grafting was low at approximately $1 \%$ among patients with atrial fibrillation in the United States. Concomitant left atrial appendage ligation was not associated with lower postoperative stroke risk. (J Thorac Cardiovasc Surg 2018;156:578-85)

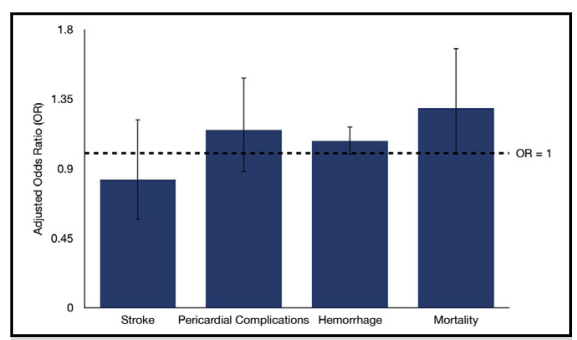

LAA ligation had similar stroke/mortality as controls after $\mathrm{CABG}$

\section{Central Message}

The postoperative stroke risk after CABG was low at approximately $1 \%$ among patients with $\mathrm{AF}$ in the United States. Concomitant LAA ligation was not associated with lower postoperative stroke risk.

\section{Perspective}

LAA is the source of greater than $90 \%$ of thrombi in patients with AF. The American Heart Association/American College of Cardiology guidelines "recommend surgical LAA ligation in cardiac surgical patients ... at risk of developing postoperative AF." Whether LAA ligation reduced stroke was controversial in the literature. We demonstrated that LAA ligation was not associated with fewer strokes after surgery. Routine LAA ligation during $\mathrm{CABG}$ is not recommended.

See Editorial Commentary page 586.
Postoperative stroke is one of the most devastating complications after coronary artery bypass grafting $(\mathrm{CABG}){ }^{1}$ occurring in approximately $3.2 \%$ of patients

From the ${ }^{\mathrm{a}}$ Center for Advanced Surgical and Interventional Technology, ${ }^{\mathrm{c}}$ David Geffen School of Medicine, and ${ }^{\mathrm{d}}$ Division of Cardiac Surgery, University of California, Los Angeles, Los Angeles, Calif; and ${ }^{\mathrm{b}}$ Department of Surgery, George Washington University, Washington, DC.

Received for publication June 28, 2017; revisions received Feb 7, 2018; accepted for publication Feb 14, 2018; available ahead of print March 31, 2018.

Address for reprints: Peyman Benharash, MD, UCLA Division of Cardiac Surgery, 10833 Le Conte Ave, UCLA Center for Health Sciences, Room 62-249, Los Angeles, CA 90095 (E-mail: Pbenharash@mednet.ucla.edu). 0022-5223/\$36.00

Copyright (C) 2018 Published by Elsevier Inc. on behalf of The American Association for Thoracic Surgery

https://doi.org/10.1016/j.jtcvs.2018.02.089 after $\mathrm{CABG}$ and $6.7 \%$ after combined $\mathrm{CABG} /$ valve surgery. ${ }^{2}$ The majority of strokes occur within the first postoperative day. ${ }^{3}$ They are believed to be atheroembolic in nature. ${ }^{4}$ Atrial fibrillation (AF) is a major known risk factor for stroke. ${ }^{5}$ Although $\mathrm{AF}$ is present in $1 \%$ to $2 \%$ of the general population ${ }^{6}$ and associated with a 5-fold increase in stroke, postoperative $\mathrm{AF}$ occurs in $16 \%$ to

- Scanning this $\mathrm{QR}$ code will take you to a supplemental video for the article. 


\section{Abbreviations and Acronyms

$\begin{array}{ll}\mathrm{AF} & =\text { atrial fibrillation } \\ \mathrm{CABG} & =\text { coronary artery bypass grafting }\end{array}$ CHA2DS2VASC $=\mathrm{C}$ : congestive heart failure (1 point), H: hypertension (1 point), A: age greater than 75 years old ( 2 points), D: diabetes mellitus (1 point), $\mathrm{S}$ : stroke (2 points), $\mathrm{V}$ : vascular disease (1 point), A: age 65-74 years (1 point), Sc: sex category (female) (1 point)

$\begin{array}{ll}\text { CI } & \text { confidence interval } \\ \text { HCUP-NIS } & \text { Healthcare Cost and Utilization } \\ & \begin{array}{l}\text { Project-Nationwide Inpatient } \\ \text { Sample }\end{array} \\ \text { ICD-9-CM } & \text { International Classification of } \\ & \text { Diseases, 9th Edition, Clinical } \\ & \text { Modification } \\ = & \text { left atrial appendage } \\ \text { LAA } & \text { odds ratio } \\ \text { OR } & \end{array}$

$30 \%$ of patients after CABG and is associated with a 1.7-fold odds of stroke. ${ }^{5}$

The left atrial appendage (LAA) is the source of greater than $90 \%$ of detected thrombi in patients with $\mathrm{AF}^{7}$ Therefore, LAA ligation has been frequently proposed as a method of reducing postoperative stroke. Results from previous randomized control trials evaluating the efficacy of LAA ligation are mixed in part because of the technical difficulties in achieving complete LAA closure. In the Left Atrial Appendage Occlusion Study, a randomized trial evaluating various methods of LAA closure, complete occlusion was attained in only $43 \%$ and $72 \%$ of patients using sutures and staples, respectively. A subsequent intention-to-treat analysis yielded no significant difference in stroke incidence between the study and control groups. ${ }^{8}$ In addition, it has been suggested that incomplete LAA ligation may increase turbulent flow and promote thrombus formation within the LAA. ${ }^{9}$ Despite these ambiguous conclusions, the "American Heart Association/American College of Cardiology/European Society of Cardiology guidelines for the management of patients with atrial fibrillation" recommend surgical LAA ligation in cardiac surgical patients "...who are at risk of developing postoperative AF." 7

Although LAA closure is primarily recommended at the time to mitral valve and antiarrhythmic operations, there is a paucity of evidence in the literature supporting this guideline recommendation in patients undergoing CABG. Furthermore, several studies have demonstrated incomplete LAA closure to paradoxically increase the risk of postoperative stroke. We aimed to perform a national database study to evaluate the impact of surgical LAA ligation in reducing postoperative stroke incidence among patients with AF undergoing $\mathrm{CABG}$.

\section{MATERIALS AND METHODS}

The Healthcare Cost and Utilization Project-Nationwide Inpatient Sample (HCUP-NIS) was a nationally representative all-payer inpatient care database, encompassing a weighted sampling of approximately $20 \%$ of all nonfederal hospital admissions in the United States. By using International Classification of Diseases, Ninth Edition, Clinical Modification (ICD-9-CM) diagnosis code 427.3, we identified patients with AF from HCUP-NIS from 2008 to 2014. Subsequently, patients who underwent $\mathrm{CABG}$ were identified using ICD-9-CM procedure codes 36.10-19. Patients who underwent CABG were categorized on the basis of the presence or absence of ICD-9-CM procedure code 37.36 corresponding to concomitant surgical LAA ligation.

Known risk factors for postoperative stroke, including age, gender, history of stroke, and comorbidities such as carotid stenosis, hypertension, congestive heart failure, diabetes mellitus, chronic kidney disease, and peripheral vascular disease, were also identified with ICD-9 diagnostic codes and the associated diagnosis-related group. Summary statistics for preoperative stroke risk were calculated using the CHA2DS2VASC [C: congestive heart failure (1 point), $\mathrm{H}$ : hypertension (1 point), A: age greater than 75 years old ( 2 points), D: diabetes mellitus (1 point), S: stroke ( 2 points), V: vascular disease (1 point), A: age 65-74 years (1 point), Sc: sex category (female) (1 point)] score, a commonly accepted clinical prediction score for stroke in patients with nonrheumatic AF. ${ }^{10}$ It was calculated using stroke risk factors as described in published formulas. ${ }^{11}$ Categoric variables were compared using the chi-square test, and continuous variables were compared using the Mann-Whitney test. Patients with missing value regarding age or gender were excluded from analyses.

To adjust for the significant differences in preoperative stroke risk between LAA ligation and control groups, a propensity score model was constructed using a 2-level mixed-effect logistic regression analysis using methods described by $\mathrm{Li}$ and colleagues, ${ }^{12,13}$ with hospital as the random-effects variable and LAA ligation as the treatment variable. This was done under the assumption that practices for patient selection for LAA ligation differ from hospital to hospital. Independent variables were selected on the basis of a priori knowledge of significant patient and operative risk factors for stroke, including age, gender, history of stroke, carotid stenosis, hypertension, congestive heart failure, diabetes, peripheral vascular disease, chronic kidney disease, concomitant valve surgery, and use of cardiopulmonary bypass. The predictive power of the propensity score estimation model was quantified using the area under receiver operating characteristic curve, also known as the C-statistic.

Univariate inverse probability-weighted logistic regressions on common support were performed to examine the difference in outcomes between patients who did and did not receive LAA ligation. The application of propensity score model construction and weighting under the constraints of complex survey data were performed in accordance with methods described by DuGoff and colleagues. ${ }^{14}$ The primary outcome of interest was postoperative in-hospital thromboembolic stroke, which was identified using a combination of ICD-9-CM diagnosis code 997.00-02, representing postoperative stroke, and 434.0, 434.1, or 434.9, representing nonhemorrhagic stroke. Secondary outcomes included pericardial complications, bleeding-related complications, mortality, and length of stay. Pericardial complications included pericardial effusion, hemopericardium, or tamponade (ICD-9-CM 423.0, 423.3, 423.9). Bleeding-related complications included hemorrhage or hematoma complicating a procedure or posthemorrhage anemia (ICD9-CM 998.11, 998.12, and 285.1). In addition, we compared the outcome of interest between the 2 groups at various CHA2DS2VASC strata. 
In addition, 2 subgroup analyses were performed. The first subgroup pertained to patients who received CABG, stratified by the use of intraoperative cardiopulmonary bypass. Patients with intraoperative cardiopulmonary bypass were identified using ICD-9 code 39.61. Analyses were performed to evaluate the efficacy of LAA ligation in reducing postoperative stroke with or without cardiopulmonary bypass. The second subgroup examined only patients in the LAA ligation group to evaluate whether the addition of concomitant Maze procedure made a difference in postoperative stroke incidence. For both subgroup analyses, similar propensity score-weighted logistic regression was used to examine the association between the procedure and outcomes of interest.

Data were stored and analyzed using Stata 13.0 software (StataCorp LP, College Station, Tex). Continuous variables were reported as mean \pm standard deviation when the underlying distribution assimilates normal distribution and as median \pm interquartile range when the underlying distribution appears skewed.

\section{RESULTS}

A total of 234,642 patients with $\mathrm{AF}$ undergoing CABG were identified during the 7-year study period. Among them, 20,664 (8.81\%) received concomitant LAA ligation, with 4762 patients $(2.03 \%)$ receiving both LAA ligation and Maze procedure. The proportion of CABG performed with LAA ligation appeared to increase from $7.89 \%$ to $13.75 \%$ over the study period $(P$ trend $<.01)$.

Baseline characteristics and postoperative stroke risk factors in the LAA ligation and control groups are shown in Table 1. There was no obvious temporal trend in median or average CHA2DS2VASC score in either group across the study period $(P$ trend $=.79)$. Despite similar CHA2DS2VASC score distribution for the 2 comparison groups (Figure 1), individual risk factors for stroke appeared to be disparate between the 2 comparison groups. Patients who received LAA ligation had a higher prevalence of age greater than 75 years, chronic kidney disease, congestive heart failure, and lower hypertension and diabetes than patients who did not. Intraoperative cardiopulmonary bypass, concomitant valve operations, and Maze procedures were all more prevalent among the LAA ligation group than in the control group $(91.0 \%$ vs $81.9 \%, \quad 36.1 \%$ vs $25.6 \%$, and $23.0 \%$ vs $7.8 \%$, respectively; $P<.01$ for all 3 comparisons).

The national incidence of postoperative stroke after CABG was $0.92 \%$ for the entire cohort. There was no significant difference in postoperative stroke incidence between the LAA ligation and control groups $(0.96 \%$ vs $0.92 \%, P=.81$ ) before matching.

Because of the significant imbalance in postoperative stroke risk profile observed between the LAA ligation and control group, a 2-level mixed-effect propensity score model was developed for estimation of likelihood to undergo LAA ligation (Table 2). The C-statistic of the propensity score model was 0.62 .

TABLE 1. Demographics and baseline stroke risk factors

\begin{tabular}{|c|c|c|c|c|}
\hline & $\begin{array}{c}\text { Control group } \\
n=213,978\end{array}$ & $\begin{array}{l}\text { LAA ligation group } \\
\quad n=20,664\end{array}$ & $\begin{array}{c}\text { Standardized mean } \\
\text { difference }\end{array}$ & $P$ value \\
\hline Age, y (Mean, SD) & $70.4 \pm 9.2$ & $72.0 \pm 8.7$ & 0.18 & $<.01$ \\
\hline Age $65-74$ y $(\mathrm{n}, \%)$ & $83,925(39.2 \%)$ & $7831(37.9 \%)$ & -0.03 & .09 \\
\hline Age $\geq 75$ y & $76,884(35.9 \%)$ & $8989(43.5 \%)$ & 0.16 & $<.01$ \\
\hline Female gender & $50,753(23.7 \%)$ & $5121(24.8 \%)$ & 0.03 & .17 \\
\hline \multicolumn{5}{|l|}{ Race } \\
\hline White & $163,691(87.2 \%)$ & $16,290(90.0 \%)$ & 0.05 & $<.01$ \\
\hline Black & $6575(3.5 \%)$ & $398(2.2 \%)$ & -0.07 & \\
\hline Hispanic & $7786(4.1 \%)$ & $610(3.4 \%)$ & -0.04 & \\
\hline Asian or Pacific Islander & $3586(1.9 \%)$ & $296(1.6 \%)$ & -0.02 & \\
\hline Native American & $940(0.5 \%)$ & $87(0.5 \%)$ & -0.01 & \\
\hline Chronic kidney disease & $29,572(13.8 \%)$ & $3272(15.8 \%)$ & 0.06 & $<.01$ \\
\hline Congestive heart failure & $53,146(24.8 \%)$ & $7692(37.2 \%)$ & 0.27 & $<.01$ \\
\hline Hypertension & $163,545(76.4 \%)$ & $14,975(72.5 \%)$ & -0.09 & $<.01$ \\
\hline Diabetes & $74,618(34.9 \%)$ & $6644(32.2 \%)$ & -0.06 & $<.01$ \\
\hline Prior stroke/transient ischemic attack/thromboembolism & $4695(2.2 \%)$ & $460(2.2 \%)$ & $<0.01$ & .89 \\
\hline Vascular disease & $33,705(15.8 \%)$ & $3008(14.6 \%)$ & -0.03 & .06 \\
\hline Intraoperative cardiopulmonary bypass & $175,298(81.9 \%)$ & $18,797(91.0 \%)$ & 0.27 & $<.01$ \\
\hline Concomitant Maze procedure & $16,697(7.8 \%)$ & $4762(23.0 \%)$ & 0.43 & $<.01$ \\
\hline Concomitant valve surgery & $54,683(25.6 \%)$ & $7453(36.1 \%)$ & 0.23 & $<.01$ \\
\hline CHA2DS2VASC (median, IQR) & $3 \pm 2$ & $3 \pm 2$ & 0.15 & $<.01$ \\
\hline
\end{tabular}

LAA, Left atrial appendage; $S D$, standard deviation; CHA2DS2VASC, C: congestive heart failure (1 point), H: hypertension (1 point), A: age greater than 75 years old (2 points),

D: diabetes mellitus (1 point), S: stroke (2 points), V: vascular disease (1 point), A: age 65-74 years (1 point), Sc: sex category (female) (1 point); IQR, interquartile range. 


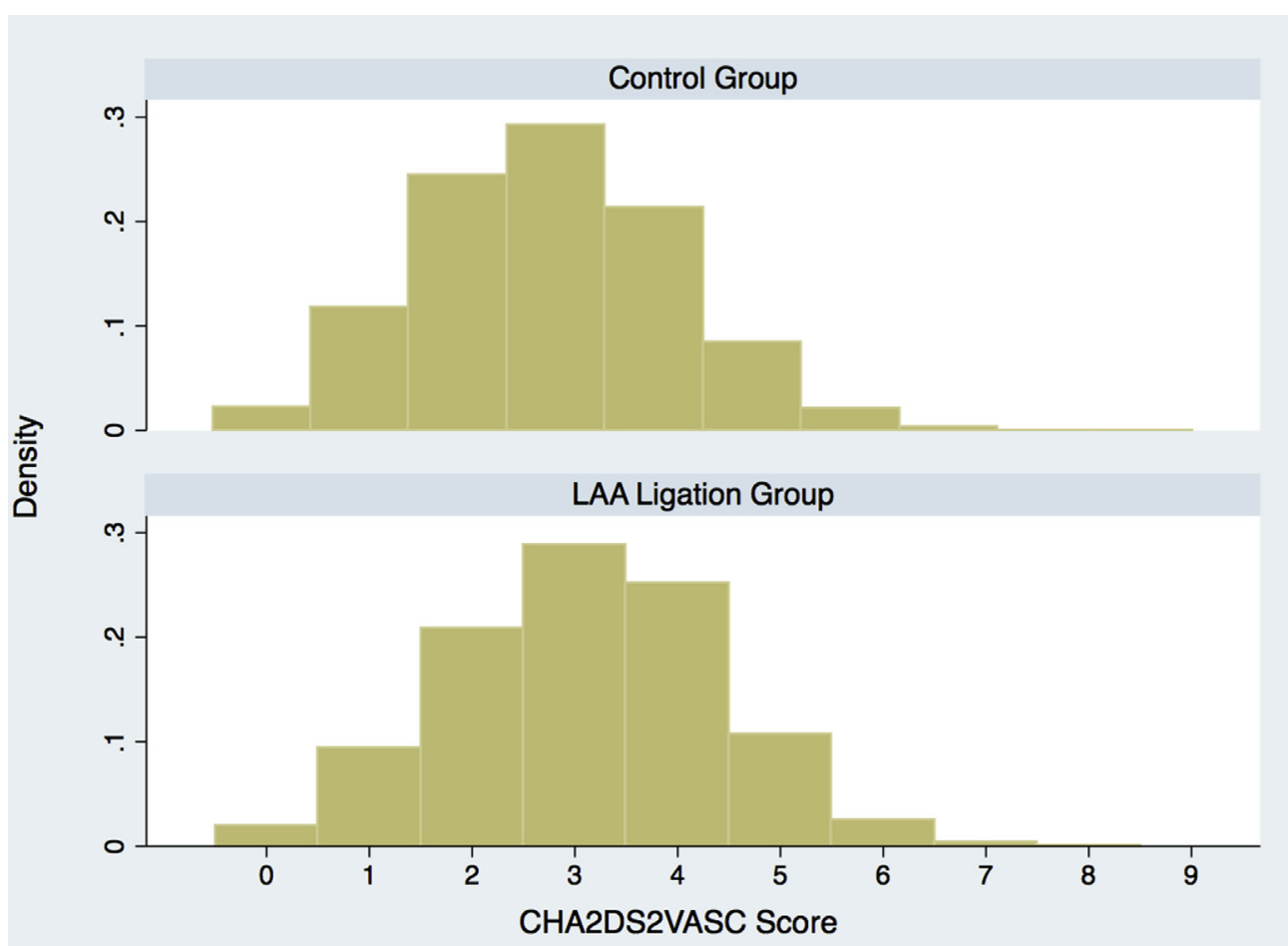

FIGURE 1. Histogram of CHA2DS2VASC distribution. Similar distribution in CHA2DS2VASC score was found between the LAA ligation and control groups. LAA, Left atrial appendage; CHA2DS2VASC, C: congestive heart failure (1 point), H: hypertension (1 point), A: age greater than 75 years old (2 points), D: diabetes mellitus (1 point), S: stroke (2 points), V: vascular disease (1 point), A: age 65-74 years (1 point), Sc: sex category (female) (1 point).

The data were weighted using transformed NIS discharge weights multiplied by normalized inverse probabilities generated by our propensity score model, as described by DuGoff and colleagues. ${ }^{14}$ Covariate balance after weighting appeared satisfactory with all standardized mean difference less than $5 \%$ between control and LAA ligation group (Table 3 and Figure 2). Subsequently, univariate logistic regressions were performed for each outcome of interest.
Results of the analysis demonstrated no significant association between LAA ligation and control with regard to postoperative stroke (odds ratio [OR], 0.83; confidence interval $[\mathrm{CI}], 0.57-1.22 ; P=.35$ ), pericardial complications (OR, 1.15; CI, 0.88-1.49; $P=.31$ ), hemorrhage or hematoma (OR, 1.08; CI, 0.99-1.17; $P=.07$ ), mortality (OR, 1.29; CI, 0.99-1.68; $P=.06$ ), and length of stay (coefficient $-0.21, \mathrm{CI},-0.44-0.02, P=.08$ ) (Figure 3).

TABLE 2. Propensity score model predicting likelihood of receiving left atrial appendage ligation among patients receiving coronary artery bypass grafting using 2-level mixed-effect logistic regression

\begin{tabular}{|c|c|c|c|}
\hline & Standardized coefficient & $\mathbf{9 5} \% \mathrm{CI}$ & $P$ value \\
\hline Age & 0.138 & $0.101-0.174$ & $<.001$ \\
\hline Female gender & -0.003 & $-0.037-0.032$ & .88 \\
\hline Carotid stenosis & -0.071 & -0.109 to -0.033 & $<.001$ \\
\hline Hypertension & -0.060 & -0.094 to -0.026 & .001 \\
\hline Congestive heart failure & 0.246 & $0.213-0.278$ & $<.001$ \\
\hline Diabetes & -0.036 & -0.072 to -0.001 & .04 \\
\hline Vascular disease & -0.045 & -0.080 to -0.009 & .01 \\
\hline Chronic kidney disease & 0.015 & -0.019 to 0.048 & .39 \\
\hline Prior stroke/transient ischemic attack/thromboembolism & -0.010 & -0.044 to 0.024 & .58 \\
\hline Intraoperative cardiopulmonary bypass & 0.259 & $0.213-0.305$ & $<.001$ \\
\hline Concomitant valve surgery & 0.108 & $0.074-0.142$ & $<.001$ \\
\hline Constant & -2.701 & -2.769 to -2.632 & $<.001$ \\
\hline
\end{tabular}

CI, Confidence interval. 
TABLE 3. Covariate balance check after propensity score weighting

\begin{tabular}{|c|c|c|c|c|}
\hline & $\begin{array}{l}\text { Mean in control } \\
\text { group }\end{array}$ & $\begin{array}{l}\text { Mean in LAA } \\
\text { ligation group }\end{array}$ & $\begin{array}{c}\text { Standardized mean } \\
\text { difference }\end{array}$ & $P$ value \\
\hline Age, y & 70.53 & 70.74 & 0.024 & .266 \\
\hline Female gender & 0.24 & 0.24 & 0.003 & .898 \\
\hline Carotid stenosis & 0.06 & 0.05 & -0.018 & .408 \\
\hline Chronic kidney disease & 0.14 & 0.15 & 0.019 & .346 \\
\hline Congestive heart failure & 0.26 & 0.27 & 0.018 & .324 \\
\hline Hypertension & 0.76 & 0.76 & 0.003 & .871 \\
\hline Diabetes & 0.35 & 0.35 & 0.009 & .670 \\
\hline Prior stroke/transient ischemic attack/thromboembolism & 0.02 & 0.02 & -0.001 & .958 \\
\hline Vascular disease & 0.16 & 0.16 & 0.002 & .937 \\
\hline Intraoperative cardiopulmonary bypass & 0.27 & 0.27 & 0.007 & .429 \\
\hline Concomitant valve surgery & 0.83 & 0.82 & -0.024 & .714 \\
\hline
\end{tabular}

LAA, Left atrial appendage.

To evaluate whether LAA ligation may confer a reduced postoperative stroke risk among patients with a particularly high-risk profile for postoperative stroke, weighted logistic regressions were performed using various CHA2DS2VASC score cutoff values to estimate the differential association between LAA ligation and postoperative stroke incidence (Table 4). However, there was no specific CHA2DS2VASC score cutoff above which LAA ligation was demonstrated to have lower postoperative stroke incidence.

The first subgroup analysis was performed by stratifying the patients into 2 subgroups: the 194,095 patients who received $\mathrm{CABG}$ with cardiopulmonary bypass (on-pump) and the 40,547 patients who received CABG without cardiopulmonary bypass (off-pump). A similar propensity score model building approach as described was used to allow performance of a propensity score-weighted logistic regression analysis. Again, there was no obvious difference in odds of postoperative stroke observed within the LAA

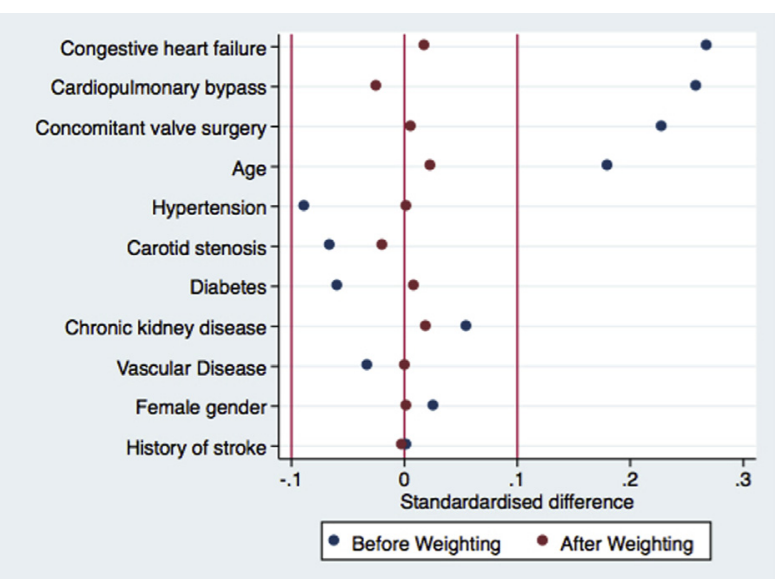

FIGURE 2. Scatterplot of the extent of covariate imbalance in terms of standardized percentage differences before and after propensity score weighting. Significant reduction in standardized differences to less than $10 \%$ for all covariates was achieved with the propensity score weighting. ligation group, either within the on-pump subgroup (OR, $0.88 ; 95 \%$ CI, $0.59-1.30 ; P=.51$ ) or the off-pump subgroup (OR, 0.34; 95\% CI, 0.07-1.58; $P=.17$ ).

The second subgroup analysis was performed within the 20,664 patients who underwent CABG with concomitant LAA ligation to assess whether the addition of Maze procedure reduced postoperative stroke. Results of the propensity score-weighted logistic regression demonstrated that the addition of Maze procedure was not associated with a reduced postoperative stroke incidence among patients who received LAA ligation (OR, 0.72; CI, 0.34-1.51; $P=.38)$.

\section{DISCUSSION}

Stroke after cardiac surgery is a devastating complication that is likely multifactorial and related to atherosclerosis and AF-related embolization. Concomitant surgical ligation of the LAA has been proposed as a strategy to reduce the risk of stroke after cardiac operations. In this retrospective national cohort study of patients undergoing $\mathrm{CABG}$, we found the addition of LAA ligation not to significantly

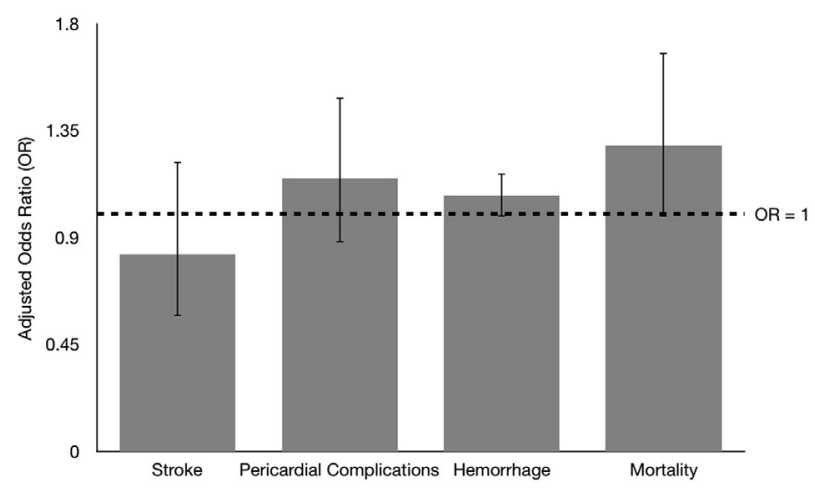

FIGURE 3. Adjusted ORs of postoperative complications associated with LAA ligation. No significant reduction in any examined postoperative complications was achieved with LAA ligation. OR, Odds ratio. 
TABLE 4. Association between left atrial appendage ligation and postoperative stroke for patients at various risk levels of stroke, as stratified by CHA2DS2VASC scores

\begin{tabular}{lccc}
\hline \multicolumn{1}{c}{$\begin{array}{c}\text { CHA2DS2VASC cutoff } \\
\text { value }\end{array}$} & \multicolumn{3}{c}{ Postoperative stroke } \\
\cline { 2 - 5 } & OR & $\mathbf{9 5} \%$ CI & $P$ value \\
\hline$>0(\mathrm{n}=46,125)$ & 0.83 & $0.57-1.22$ & .35 \\
$>1(\mathrm{n}=40,658)$ & 0.83 & $0.57-1.22$ & .35 \\
$>2(\mathrm{n}=29,269)$ & 0.82 & $0.56-1.20$ & .30 \\
$>3(\mathrm{n}=15,484)$ & 0.80 & $0.54-1.20$ & .29 \\
$>4(\mathrm{n}=5262)$ & 0.86 & $0.53-1.39$ & .53 \\
$>5(\mathrm{n}=1185)$ & 1.08 & $0.54-2.16$ & .82 \\
$>6(\mathrm{n}=180)$ & 2.15 & $0.58-7.94$ & .25 \\
$>7(\mathrm{n}=17)$ & N/A & N/A & N/A \\
\hline
\end{tabular}

CHA2DS2VASC, C: congestive heart failure (1 point), $\mathrm{H}$ : hypertension (1 point), A: age greater than 75 years old (2 points), D: diabetes mellitus (1 point), S: stroke ( 2 points), V: vascular disease (1 point), A: age $65-74$ years ( 1 point), Sc: sex category (female) (1 point); $O R$, odds ratio; $C I$, confidence interval; N/A, not available.

reduce postoperative stroke risk. In addition, the conclusion held true for all subcohorts of patients with various stroke risk, as stratified by the CHA2DS2VASC score. Concomitant Maze procedure at the time of LAA ligation did not alter this outcome (Video 1).

Although LAA ligation has been found to be effective in reducing postoperative stroke incidence ${ }^{15}$ after valvular operations, whether LAA ligation should be applied to the other most commonly performed cardiac operation, CABG remains controversial in the literature. An institutional case series by Kim and colleagues ${ }^{16}$ consisting of $90.9 \%$ CABG cases documented the reduction of postoperative stroke incidence from $6.1 \%$ to $0 \%$ in a propensity score-matched analysis, whereas another series of off-pump CABG cases showed a reduction of early stroke risk from $2.8 \%$ to $1.6 \%$. On the other hand, results from a prospective randomized control study, the Left Atrial Appendage Occlusion Study, demonstrated no significant difference in short-term postoperative stroke. ${ }^{11,17} \mathrm{~A}$

\section{Does Left Atrial Appendage Ligation during Coronary Bypass Surgery Decrease the Incidence of Postoperative Stroke?}

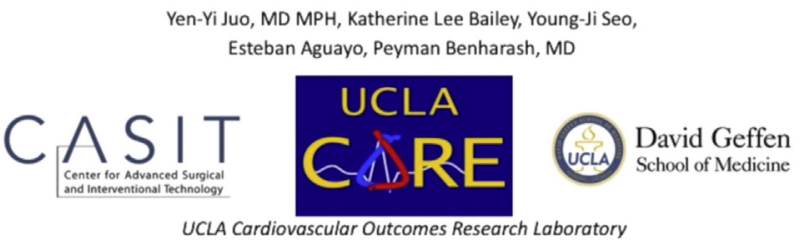

VIDEO 1. Dr Juo, the first author and principal statistician of this study, explains the background, major findings, and key relevance of our study. Video available at: http://www.jtcvsonline.org/article/S0022-5223(18) 30718-9/fulltext. systematic review/meta-analysis evaluating surgical LAA occlusion during cardiac surgery for patients with $\mathrm{AF}$ pooled results from both $\mathrm{CABG}$ and valvular procedures and concluded that stroke incidence was significantly reduced from $1.9 \%$ to $0.95 \%$ with LAA occlusion. ${ }^{18}$

We believe the frequently contradictory conclusions drawn by various investigators may be explained by 2 main factors: First, postoperative stroke after CABG is relatively uncommon compared with valvular operations. ${ }^{19-21}$ Using identical ICD-9-CM diagnostic codes to query HCUP-NIS, we found an average $0.92 \%$ in-hospital stroke incidence after CABG in comparison with $2.5 \%$ to $4.6 \%$ after valvular surgery in a previous study. ${ }^{15}$ The low stroke risk nature of the procedure may preclude patients from receiving additional benefit from LAA ligation, because the currently observed post-CABG stroke incidence may represent emboli from other sources such as the aorta or the carotid artery that would not be affected with LAA ligation. The use of an off-pump approach in select patients has been shown to further decrease the post-CABG stroke incidence in several studies. ${ }^{18,22}$ To address the question regarding efficacy of LAA ligation in patients receiving CABG under an off-pump approach, we have performed a sensitivity analysis in which we have demonstrated that LAA ligation was not associated with a lower postoperative stroke incidence with or without cardiopulmonary bypass.

The next factor has to do with the technical difficulty in achieving complete LAA occlusion. Studies have documented a failure rate between $30 \%$ and $40 \%$, depending on the anatomy, surgeon experience, and technique. ${ }^{23,24}$ Therefore, the effect size of LAA ligation in reducing stroke risk may be frequently obscured by the presence of significant proportions of patients with incomplete occlusion. Unless routine postoperative transesophageal echocardiography is performed, it would be difficult to ascertain whether the observed effect was a result of LAA ligation or complications arising from an incomplete LAA ligation. However, several new surgical devices have recently become commercially available. ${ }^{25}$ One epicardial clip occlusion device was found to allow successful LAA closure in $98.4 \%$ of patients ${ }^{26}$ and satisfactory long-term clip stability. ${ }^{25}$ In addition, percutaneous LAA closure devices may represent reasonable alternatives for stand-alone LAA closure with a higher technical success rate. With the increasing adoption of these new devices, successful LAA closure may be easier to achieve than the past and warrant a reevaluation of its true efficacy, undiluted by complications from incomplete closures.

In addition to its controversial efficacy, conventional LAA ligation may be associated with certain complications. An incomplete LAA ligation has been shown to lead to blood stagnation ${ }^{27}$ and a paradoxical increase in the risk 
of stroke risk. ${ }^{28,29}$ In addition, our study demonstrated a marginal increase in mortality and bleeding-related complications among the cohort who received concomitant LAA ligation. We speculate that this may be due to the prolonged operative time and the additional insult of a cardiotomy that would otherwise not have been made. Secondary outcomes like these were rarely examined in the surgical LAA ligation case series, in which the outcome of focus remained stroke only. ${ }^{8,27}$ Unlike valve surgeries, CABG, when performed without LAA ligation, does not involve access into the atrium. We believe this additional level of invasion may be partly responsible for the observed elevated complication risks.

\section{Study Limitations}

There are several limitations with our study, the most important of which relates to the lack of clear distinction between patients with preexisting $\mathrm{AF}$ and those with postoperative $\mathrm{AF}$ because of the lack of a specific diagnosis code identifying AF as a surgical complication. According to Nationwide Inpatient Sample data element definition, all captured AF diagnoses in this study represent preoperative $\mathrm{AF}$, and there is no available diagnosis code for identifying postoperative AF. There was also no specific diagnosis code for identifying patients receiving anticoagulants. In addition, we believe the patient's cerebrovascular event history may be undercoded because of the low observed prevalence. Individual coding practices at participating hospitals could lead to substantial misclassification bias on an aggregate level in administrative databases such as the HCUP-NIS. The confounding effect of this phenomenon is especially apparent in smaller subgroups, when the residual covariate imbalance could not be satisfactorily adjusted, such as during the CHA2DS2VASC-stratified analysis in the current study, in which an apparent trend toward higher stroke incidence was observed among patients with higher CHA2DS2VASC. On closer inspection, one realizes that this appearance was due to the relatively smaller sample size and higher CI among the few patients with high CHA2DS2VASC score rather than a real association. Finally, clinical parameters that might confound the conclusion, including the true success rate of appendage exclusion and intraoperative techniques in aortic manipulation, were not available from the database. Nonetheless, the large sample size examined provides convincing evidence that concomitant surgical LAA ligation without additional qualifications does not effectively reduce the risk of postoperative stroke in patients who undergo CABG.

\section{CONCLUSIONS}

To our knowledge, the present work represents the only examination of a large national cohort evaluating the impact of surgical LAA closure for patients with AF undergoing
CABG in reducing postoperative stroke risk. We have demonstrated that postoperative stroke risk was low at approximately $1 \%$ among patients with $\mathrm{AF}$ receiving CABG in the United States. In addition, when weighted with inverse probability of baseline stroke risk, those who underwent concomitant LAA ligation did not experience lower stroke incidence than the control group. In view of the doubtful efficacy of present surgical methods for LAA ligation in reducing stroke risk after $\mathrm{CABG}$, possible improvement in atrial contractility with LAA preservation, ${ }^{30}$ and trends toward increased bleeding with LAA exclusion, ${ }^{8}$ we do not recommend traditional surgical LAA ligation during CABG. Future research efforts are indicated to evaluate the impact of more secure novel LAA occlusion devices in the outcomes of patients who undergo $\mathrm{CABG}$.

\section{Conflict of Interest Statement}

Authors have nothing to disclose with regard to commercial support.

\section{References}

1. Roach GW, Kanchuger M, Mangano CM, Newman M, Nussmeier N, Wolman R, et al. Adverse cerebral outcomes after coronary bypass surgery. Multicenter Study of Perioperative Ischemia Research Group and the Ischemia Research and Education Foundation Investigators. N Engl J Med. 1996;335:1857-63.

2. Salazar JD, Wityk RJ, Grega MA, Borowicz LM, Doty JR, Petrofski JA, et al. Stroke after cardiac surgery: short- and long-term outcomes. Ann Thorac Surg. 2001;72:1195-202.

3. Likosky DS, Marrin CA, Caplan LR, Baribeau YR, Morton JR, Weintraub RM, et al. Determination of etiologic mechanisms of strokes secondary to coronary artery bypass graft surgery. Stroke. 2003;34:2830-4.

4. Blauth CI. Macroemboli and microemboli during cardiopulmonary bypass. Ann Thorac Surg. 1995;59:1300-3.

5. Stamou SC, Hill PC, Dangas G, Pfister AJ, Boyce SW, Dullum MK, et al. Stroke after coronary artery bypass: incidence, predictors, and clinical outcome. Stroke. 2001;32:1508-13.

6. Naccarelli GV, Varker H, Lin J, Schulman KL. Increasing prevalence of atrial fibrillation and flutter in the United States. Am J Cardiol. 2009;104:1534-9.

7. Fuster V, Ryden LE, Cannom DS, Crijns HJ, Curtis AB, Ellenbogen KA, et al. $2011 \mathrm{ACCF} / \mathrm{AHA} / \mathrm{HRS}$ focused updates incorporated into the ACC/AHA/ESC 2006 Guidelines for the management of patients with atrial fibrillation: a report of the American College of Cardiology Foundation/American Heart Association task force on practice guidelines developed in partnership with the European Society of Cardiology and in collaboration with the European Heart Rhythm Association and the Heart Rhythm Society. J Am Coll Cardiol. 2011;57:e101-98.

8. Healey JS, Crystal E, Lamy A, Teoh K, Semelhago L, Hohnloser SH, et al. Left Atrial Appendage Occlusion Study (LAAOS): results of a randomized controlled pilot study of left atrial appendage occlusion during coronary bypass surgery in patients at risk for stroke. Am Heart J. 2005;150:288-93.

9. Katz ES, Tsiamtsiouris T, Applebaum RM, Schwartzbard A, Tunick PA, Kronzon I. Surgical left atrial appendage ligation is frequently incomplete: a transesophageal echocardiographic study. J Am Coll Cardiol. 2000;36:468-71.

10. Gage BF, Waterman AD, Shannon W, Boechler M, Rich MW, Radford MJ Validation of clinical classification schemes for predicting stroke: results from the National Registry of Atrial Fibrillation. JAMA. 2001;285:2864-70.

11. Gage BF, van Walraven C, Pearce L, Hart RG, Koudstaal PJ, Boode BS, et al. Selecting patients with atrial fibrillation for anticoagulation: stroke risk stratification in patients taking aspirin. Circulation. 2004;110:2287-92.

12. Schuler MS, Chu W, Coffman D. Propensity score weighting for a continuous exposure with multilevel data. Health Serv Outcomes Res Methodol. 2016;16: 271-92.

13. Arpino B, Mealli F. The specification of the propensity score in multilevel observational studies. Comput Stat Data Anal. 2011;55:1770-80. 
14. Dugoff EH, Schuler M, Stuart EA. Generalizing observational study results: applying propensity score methods to complex surveys. Health Serv Res. 2014; 49:284-303.

15. Elbadawi A, Olorunfemi O, Ogunbayo GO, Saad M, Elgendy IY, Arif Z, et al. Cardiovascular outcomes with surgical left atrial appendage exclusion in patients with atrial fibrillation who underwent valvular heart surgery (from the National Inpatient Sample Database). Am J Cardiol. 2017:119:2056-60.

16. Kim R, Baumgartner N, Clements J. Routine left atrial appendage ligation during cardiac surgery may prevent postoperative atrial fibrillation-related cerebrovascular accident. J Thorac Cardiovasc Surg. 2013;145:582-9.

17. Crystal E, Lamy A, Connolly SJ, Kleine P, Hohnloser SH, Semelhago L, et al. Left Atrial Appendage Occlusion Study (LAAOS): a randomized clinical trial of left atrial appendage occlusion during routine coronary artery bypass graft surgery for long-term stroke prevention. Am Heart J. 2003;145:174-8.

18. Tsai YC, Phan K, Munkholm-Larsen S, Tian DH, La Meir M, Yan TD. Surgical left atrial appendage occlusion during cardiac surgery for patients with atrial fibrillation: a meta-analysis. Eur J Cardiothorac Surg. 2015;47: 847-54.

19. Blackshear JL, Odell JA. Appendage obliteration to reduce stroke in cardiac surgical patients with atrial fibrillation. Ann Thorac Surg. 1996;61:755-9.

20. Hogue CW Jr, Barzilai B, Pieper KS, Coombs LP, DeLong ER, Kouchoukos NT, et al. Sex differences in neurological outcomes and mortality after cardiac surgery: a society of thoracic surgery national database report. Circulation. 2001;103:2133-7.

21. Orszulak TA, Schaff HV, Pluth JR, Danielson GK, Puga FJ, Ilstrup DM, et al. The risk of stroke in the early postoperative period following mitral valve replacement. Eur J Cardiothorac Surg. 1995;9:615-20.

22. Sa MP, Ferraz PE, Esobar RR, Martins WN, Lustosa PC, Nunes O, et al. Off-pump versus on-pump coronary artery bypass surgery: meta-analysis and meta-regression of 13,524 patients from randomized trials. Rev Bras Cir Cardiovasc. 2012;27:631-41.

23. Johnson WD, Ganjoo AK, Stone CD, Srivyas RC, Howard M. The left atrial appendage: our most lethal human attachment! Surgical implications. Eur J Cardiothorac Surg. 2000;17:718-22.

24. Aryana A, d'Avila A. Incomplete closure of the left atrial appendage: implication and management. Curr Cardiol Rep. 2016;18:82.

25. Suwalski G, Emery R, Gryszko L, Kaczejko K, Zegadlo A, Frankowska E, et al Early operative comparison of two epicardial left atrial appendage occluding systems applied during off-pump coronary revascularisation in patients with persistent atrial fibrillation. Kardiochir Torakochirurgia Pol. 2016;13:10-4.

26. Ailawadi G, Gerdisch MW, Harvey RL, Hooker RL, Damiano RJ Jr, Salamon T, et al. Exclusion of the left atrial appendage with a novel device: early results of a multicenter trial. J Thorac Cardiovasc Surg. 2011;142:1002-9. 1009.e1001.

27. Schneider B, Stollberger C, Sievers HH. Surgical closure of the left atria appendage—a beneficial procedure? Cardiology. 2005;104:127-32.

28. Aryana A, Singh SK, Singh SM, O'Neill PG, Bowers MR, Allen SL, et al, Association between incomplete surgical ligation of left atrial appendage and stroke and systemic embolization. Heart Rhythm. 2015;12:1431-7.

29. Cullen MW, Stulak JM, Li Z, Powell BD, White RD, Ammash NM, et al. Left atrial appendage patency at cardioversion after surgical left atrial appendage intervention. Ann Thorac Surg. 2016;101:675-81.

30. Yamanaka K, Sekine Y, Nonaka M, Iwakura A, Yoshitani K, Nakagawa Y, et al. Left atrial appendage contributes to left atrial booster function after the maze procedure: quantitative assessment with multidetector computed tomography Eur J Cardiothorac Surg. 2010;38:361-5.

Key Words: coronary artery bypass graft, left atrial appendage, stroke, atrial fibrillation 